\title{
Mladteüge und Bexidgtigungen.
}

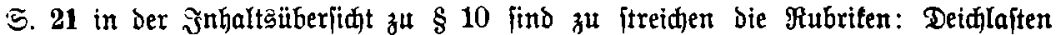
und gemeine Lajten (Begriff). Statt Förberungen lię ebenbort Forbe=

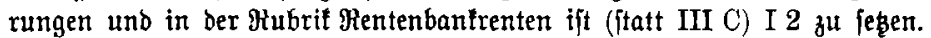

"25 ift 1. bor Begriff in Rubril C. zu itreichert.

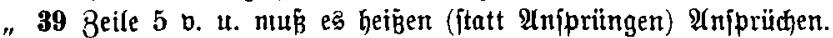

"64 in $\$ 23$ in 2 trm. 6 a. (5. muß e马 heiken (ftatt Bejdlugnalyme) Bejđlag= nahme.

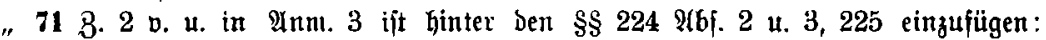
3PD.

" 79 Urm. 1 2Hbj. 2 Beife 6 ift zน lejen Beibringung (ĩtatt Bebringung).

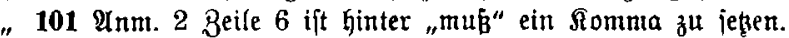

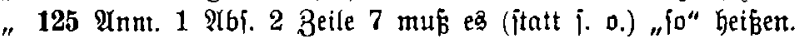

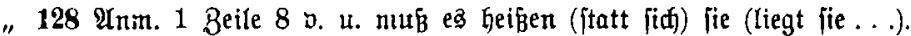

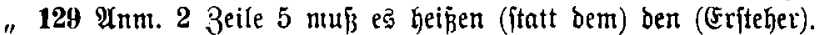

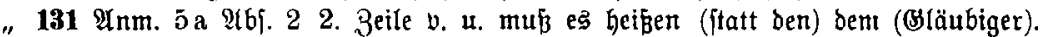

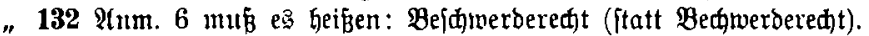

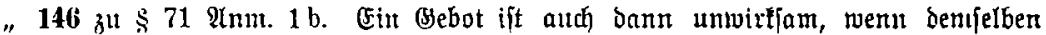
ein Jrtunt Des Bieters (\$S 119, 121 B(SB.) Jugrunde liegt und bas

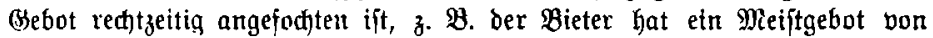
9000 Mit. abgegeben uno hat nut cin foldes bon 900 Talern abgeben wollen. Fiøt ber Bieter nod) im Berfteigerungstermin wegen Эrrtums

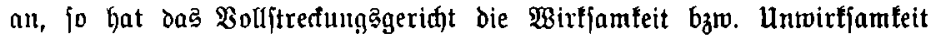

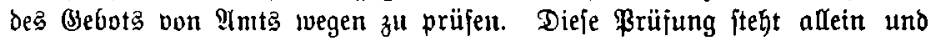

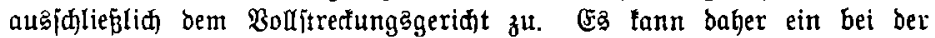

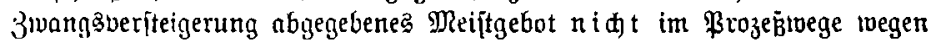

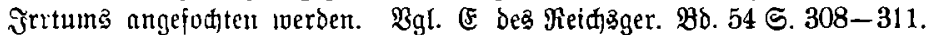

"16\% Zeile 2 von oben ift zu ntederfolet vor "bie“ unb hinter "bazw." "Durd)“.

" 164 2lnm. 1 Ubi. 2 3eile 4 ift hinter "Nidftigfeit“ ber \$unft zu ftreiden uno itatt beijen ein Somma zu iezen.

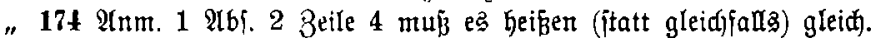

" 179 lebte Beile mús es Geißren (itaft o) po.

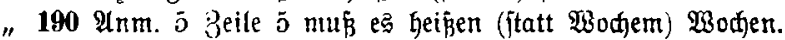


5. 199 Beile 12 v. o. ift Ginter Beträge zo jekenen :

" 199 Annt. 3 Beile 10 mußs es Geipen (jtatt jeden) jebem.

" 202 leşte Beile mú

" 203 धnm. 3 Beile 6 mus ez heízen (jtatt de) Der.

" 207 in ber britten überiळrift ift hinter "befugh" ein Romma zat feben.

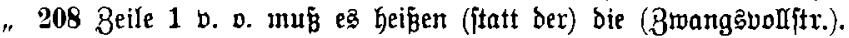

" 211 Beile 6 v. v. ift hinter "Bef." ein Fomma zu lebent.

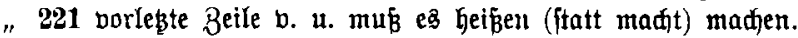

" 228 21nm. 2 by ijt hinter "ift“ (jtatt .) ein Semilolon zu ferzen.

" 245 Anm. 2 zeile 2 muв ę Geißen (itatt zuzuführen) zu führen.

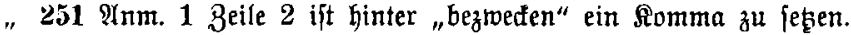

"263 Beile 2 v. o. mú ез Geißen: befürdten (ftatt befurdten).

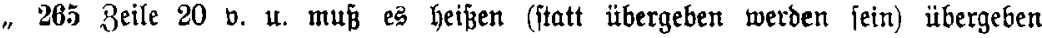
toorber find.

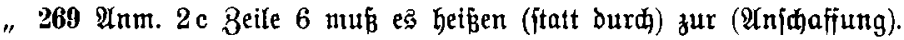

" 290 भrm. 2 c Beile 7 ift "fid“ zu ftreichen.

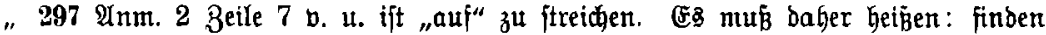

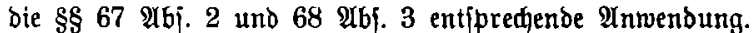

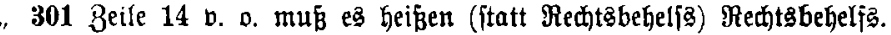

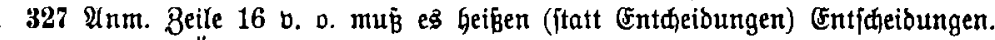

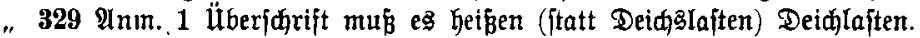

" 349 Anm. 2 Beile 1 mus es heísen (jtatt enthaltene) enthalten.

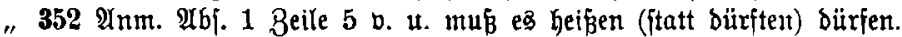

